\title{
Molecular markers associated with outcome and metastasis in human pancreatic cancer
}

\author{
Anke Van den Broeck ${ }^{1,2}$, Hugo Vankelecom², Rudy Van Eijsden³, Olivier Govaere ${ }^{4}$ and Baki Topal ${ }^{1 *}$
}

\begin{abstract}
Background: Pancreatic ductal adenocarcinoma (PDAC) is a heterogeneous cancer in which differences in survival rates might be related to a variety in gene expression profiles. Although the molecular biology of PDAC begins to be revealed, genes or pathways that specifically drive tumour progression or metastasis are not well understood.

Methods: We performed microarray analyses on whole-tumour samples of 2 human PDAC subpopulations with similar clinicopathological features, but extremely distinct survival rates after potentially curative surgery, i.e. good outcome (OS and DFS $>50$ months, $n=7$ ) versus bad outcome (OS $<19$ months and DFS $<7$ months, $n=10$ ). Additionally, liver- and peritoneal metastases were analysed and compared to primary cancer tissue $(n=11)$.

Results: The integrin and ephrin receptor families were upregulated in all PDAC samples, irrespective of outcome, supporting an important role of the interaction between pancreatic cancer cells and the surrounding desmoplastic reaction in tumorigenesis and cancer progression. Moreover, some components such as ITGB1 and EPHA2 were upregulated in PDAC samples with a poor outcome, Additionally, overexpression of the non-canonical Wnt/ $\beta$-catenin pathway and EMT genes in PDAC samples with bad versus good outcome suggests their contribution to the invasiveness of pancreatic cancer, with $\beta$-catenin being also highly upregulated in metastatic tissue.
\end{abstract}

Conclusions: Components of the integrin and ephrin pathways and EMT related genes, might serve as molecular markers in pancreatic cancer as their expression seems to be related with prognosis.

Keywords: Pancreatic cancer, Surgery, Biomarker

\section{Background}

Pancreatic ductal adenocarcinoma (PDAC) remains a major cause of cancer related death, despite advances in surgical and medical care [1]. The majority of patients present with locally advanced or metastatic disease and die within 6-12 months. Even in the selected group of prognostic favourable localized and resectable PDAC, the 5 -year overall survival (OS) is only $10-25 \%$ as the majority of patients develop disease relapse within two years after potentially curative treatment [2]. Additionally, the effect of systemic chemotherapy, either in adjuvant or in palliative setting, is low [3].

Although some parameters are described to be prognostic factors after curative surgery, such as lymph node and resection margin status, none has been consistently

\footnotetext{
* Correspondence: baki.topal@med.kuleuven.be

'Department of Abdominal Surgery, University Hospitals Leuven, Leuven, Belgium

Full list of author information is available at the end of the article
}

related to overall survival [4,5]. Moreover, even in patients with similar clinicopathological parameters, a wide range of survival rates is observed postoperatively [2]. This heterogeneous biology of pancreatic cancer and possibly related diverse response to treatment might be explained by differences in gene expression profiles. At present, molecular characteristics of PDAC carcinogenesis become gradually unravelled, but genes or pathways that specifically drive tumour progression or metastasis are not well understood [6,7]. Some studies have already linked gene expression profiles with lymph node status or advanced PDAC stage, but results are inconsistent [810]. Recently, a gene signature that subdivides PDAC in 3 subtypes was developed based on gene expression from microdissected PDAC material and cell lines. This signature would have a prognostic value and would be predictive for drug responses [11]. Microdissected material and cell lines however do not comprise the complexity of pancreatic cancer. PDAC is characterized by

\section{Biomed Central}


an abundant desmoplastic reaction that has long been ignored, but is now known to play an important role in PDAC tumorigenesis and progression [12,13].

Therefore, the aim of the present study was to define molecular characteristics related to pancreatic cancer progression, based on whole genome expression profiling of 2 human PDAC subgroups with similar clinicopathological features, but with extremely distinct survival rates after curative surgery. Additionally, we tried to gain more insight in the metastatic process of PDAC by comparing gene expression profiles of liver- and peritoneal metastases with that of primary tumour samples.

\section{Methods}

\section{Primary PDAC and metastatic samples}

Patients who underwent surgical treatment for PDAC between 1998 and 2008 were studied. Immediately after surgical removal of the resection specimen, a small part of the tissue was snap-frozen in liquid nitrogen and stored at $-80^{\circ} \mathrm{C}$; the other part was fixed in $6 \%$ formol and embedded in paraffin for histological examination. From patients with metastatic disease undergoing palliative surgery, core biopsies of the primary tumour and of liver (LM)/peritoneal (PM) metastases were taken and processed in a similar way. Haematoxylin-Eosin (H\&E) staining was performed on each sample for histopathological confirmation according to the World Health Organization criteria. The study was approved by the KU Leuven ethical committee prior to patient recruitment, and received the study number ML3452.

Clinical and histopathological data from all patients were registered in a prospective database. Disease recurrence was defined as local or distant recurrence, diagnosed on follow-up imaging, performed routinely or because of elevated serum tumour markers.

\section{Classification of PDAC with good or bad outcome}

One hundred fifty-five patients suffering from PDAC were operated with curative intent. Postoperative followup was complete and closed in December 2011. Survival curves were determined using the Kaplan-Meier lifetable technique. The median overall (OS) and diseasefree survival (DFS) was respectively 22.3 months (95\% confidence interval (CI) $18.7-29.0 \mathrm{~m}$ ) and 12.0 months (CI: 9.0-13.3 m). None of these patients received preoperative or neo-adjuvant treatment. Postoperative chemotherapy $(n=69)$ or chemoradiation $(n=29)$ did not influence OS or DFS in this patient group. Based on cumulative OS and DFS probability plots (Figure 1A), we defined two patient subgroups: one group with an exceptional good outcome (defined as 'Good': OS and DFS $>50$ months, $n=17$ ), and one group with an exceptional poor outcome (defined as 'Bad': OS $<19.5$ months and $\mathrm{DFS}<7$ months, $\mathrm{n}=47$ ) (Figure $1 \mathrm{~B}$ ).

\section{Whole-genome expression analysis}

Only representative snap-frozen PDAC material- defined as a minimum of $30 \%$ cancer cells on H\&E staining was used for RNA extraction. In order not to exclude tumour microenvironment for gene expression analysis, samples were used without microdissection. Total RNA was extracted using Trizol (Invitrogen, Grand Island, NY) and the RNeasy mini kit (Qiagen, Venlo, The Netherlands) according to the manufacturer's guidelines. RNA concentration and purity were determined spectrophotometrically using the Nanodrop ND-1000 (Nanodrop Technologies, Wilmington, DE) and RNA integrity was assessed using a Bioanalyser 2100 (Agilent Technologies, Santa Clara, CA). Only samples with a RIN of at least 7.1 were used for further microarray analysis at the VIB Nucleomics Core (www.nucleomics.be).

Per sample, an amount of $100 \mathrm{ng}$ of total RNA spiked with bacterial RNA transcript positive controls (Affymetrix) was amplified and labelled using the GeneChip 3' IVT express kit (Affymetrix). All steps were carried out according to the manufacturer's protocol. A mixture of purified and fragmented biotinylated aRNA and hybridisation controls (Affymetrix) was hybridised on Affymetrix HG U133 Plus 2.0 arrays followed by staining and washing in a GeneChip ${ }^{\circledR}$ fluidics station 450 (Affymetrix) according to the manufacturer's procedures. To assess the raw probe signal intensities, chips were scanned using a GeneChip ${ }^{\circledR}$ scanner 3000 (Affymetrix).

The RMA procedure was used to normalize data within arrays (background correction and $\log ^{2}$-transformation) and between arrays (quintile normalization) (affy_1.22.0 package of Bioconductor) [14,15]. The MAS 5.0 algorithm (Microarray suite user guide, version 5; Affymetrix 2001) was used to assess detection above background. All probesets had a good signal and were used for further analysis. Four experimental designs were analysed: the effect of PDAC patients with a good outcome ('Good') versus surrounding pancreatic tissue (defined as 'control'), the effect of PDAC patients with a poor outcome ('Bad') versus surrounding pancreas, the effect of 'Bad' versus 'Good' and the effect of all PDAC samples, irrespective of outcome, versus metastatic disease in the liver or peritoneum. The limma package from Bioconductor was used to assess the contrast in each experiment [16]. Statistical significance of this contrast was tested with a moderated $\mathrm{t}$-test (implemented in limma). Differentially expressed genes were defined as genes with an uncorrected $\mathrm{p}$-value of $\mathrm{p}<0.001$ in combination with $>2$ fold-change. Classical schemes to adjust for multiple testing can result in low statistical power for microarray studies . The stringent cut-off of $\mathrm{p}<0.001$ was used as an alternative, pragmatic approach to balance the number of false positives and false negatives [17].

Metastatic samples (LM and PM) were contaminated with respectively normal liver and peritoneal tissue, 

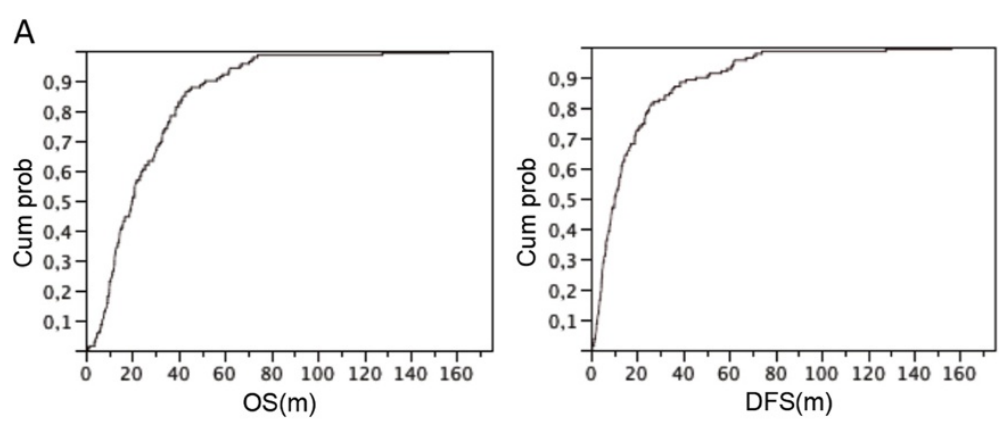

B

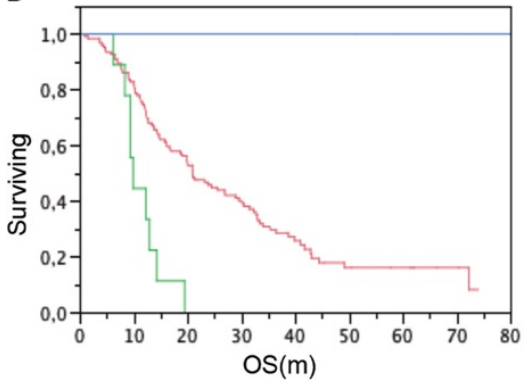

Figure 1 Classification of PDAC patients based on outcome data. (A) Cumulative curve for overall survival (OS, left) and disease-free survival (DFS, right), based on survival data of all PDAC patients with representative snap-frozen material. (B) Kaplan-Meier overall survival curve of patients respectively from the 'Good' (blue) and 'Bad' (green) outcome group, in comparison with the non-classified patients (red).

reflecting in upregulation of liver- and peritoneal specific genes. Therefore only genes that were not differentially expressed between LM and PM samples, considered as metastatic specific genes, were used for analysis between primary tumour and metastatic tissue.

All gene expression data will be available from the Gene Expression Omnibus (GEO, http://www.ncbi.nlm. nih.gov/projects/geo/).

Functional pathway analysis on differentially expressed probe sets was done with the Ingenuity Pathway Analysis (IPA) program (Ingenuity Systems, www.ingenuity. com; Redwood City, CA). For each experiment, probe sets with a corrected p-value $<0.001$ and a $>2$ fold change were used as input. If multiple probes referred to the same molecule, the average of the log-ratio values was taken for further analysis. Generated networks were ordered by a score meaning significance, estimated as the ratio of the number of input probes that map to the pathway divided by the total number of pathway probes. Significance of biological functions and canonical pathways were tested by the Fisher's exact test p-value after application of Benjamini- Hochberg method of multiple testing correction. Significant pathways were chosen as $\mathrm{p}<0.05$, except for the significant canonical pathways in the 'Good' versus control experiment where a more stringent $\mathrm{p}$-value $(\mathrm{p}<0.01)$ was chosen to eliminate possible false-positive results due to the large number of differentially expressed probe sets.
For each experiment, additional KEGG (Kyoto Encyclopedia of Genes and Genomes) pathway analysis was performed on up- or downregulated genes (corrected p-value $<0.001$ and a fold change of respectively $>2$ and $<2$ ) using GENECODIS, a web-based tool for enrichment analysis (http://genecodis.dacya.ucm.es ) using the NCBI Entrez Gene database [18]. Two statistical tests are implemented: the hypergeometric distribution and the $x^{2}$ test of independence. A stimulation-based correction approach is used to adjust for multiple testing.

\section{Results}

\section{Sample selection}

Based on the definition of the 2 diverse survival outcome groups and the required RIN values above 7.1, finally 7 'Good' and 10 'Bad' patient samples with similar pathological characteristics remained available for gene expression analysis (Table 1, Figure 2). The median age was 61 and 67 years, respectively. All patients had negative resection margins on histopathological examination.

Additionally, 6 surrounding non-tumoural pancreatic control samples, 7 LM and 4 PM fulfilled the quality criteria and were used for microarray analysis.

\section{Gene expression profiling of 'Good' PDAC versus control}

Analysis of 'Good' versus control samples revealed 3265 differentially expressed probe sets, of which 2806 could be mapped to genes in the Ingenuity Knowledge Base. 
Table 1 Clinicopathological parameters of patients, with respectively good and bad outcome

\begin{tabular}{|c|c|c|c|c|c|c|c|c|c|c|c|c|c|c|}
\hline Category & Gender & Age & Location & pG & pT & $\mathrm{pN}$ & $\mathrm{pM}$ & $\mathrm{pR}$ & PNI & LVI & VI & Postop & OS & DFS \\
\hline GOOD & $\mathrm{F}$ & 55 & Head & 2 & 2 & 0 & 0 & 0 & 1 & 0 & 1 & 0 & 156.4 & 156.4 \\
\hline GOOD & M & 32 & Head & 3 & 3 & 1 & 0 & 0 & 1 & 1 & 0 & RCT & 127.9 & 127.9 \\
\hline GOOD & M & 78 & Head & 1 & 3 & 0 & 0 & 0 & 0 & 1 & 0 & 0 & 71.5 & 71.5 \\
\hline GOOD & M & 53 & Head & 3 & 3 & 1 & 0 & 0 & 1 & 0 & 1 & RCT & 67.2 & 67.2 \\
\hline GOOD & $\mathrm{F}$ & 61 & Head & 3 & 3 & 0 & 0 & 0 & 1 & 0 & 1 & 0 & 56.4 & 56.4 \\
\hline GOOD & $\mathrm{F}$ & 62 & Head & 3 & 3 & 1 & 0 & 0 & 0 & 0 & 1 & RCT & 62.7 & 62.7 \\
\hline GOOD & M & 68 & Tail & 3 & 2 & 0 & 0 & 0 & 1 & 0 & 1 & $\mathrm{CT}$ & 51.5 & 51.5 \\
\hline BAD & $\mathrm{F}$ & 75 & Head & 3 & 3 & 0 & 0 & 0 & 1 & 0 & 0 & 0 & 9.4 & 5.2 \\
\hline BAD & M & 72 & Head & 2 & 3 & 1 & 0 & 0 & 1 & 1 & 1 & $C T$ & 12.6 & 5.6 \\
\hline BAD & M & 52 & Head & 3 & 3 & 0 & 0 & 0 & 1 & 0 & 1 & 0 & 8.4 & 4.1 \\
\hline BAD & $\mathrm{F}$ & 78 & Head & 2 & 3 & 1 & 0 & 0 & 1 & 1 & 1 & 0 & 9.9 & 3.6 \\
\hline BAD & $M$ & 59 & Head & 3 & 3 & 1 & 0 & 0 & 1 & 0 & 0 & 0 & 6.3 & 2.8 \\
\hline BAD & $\mathrm{F}$ & 51 & Head & 3 & 3 & 0 & 0 & 0 & 0 & 0 & 0 & $C T$ & 19.4 & 6.5 \\
\hline BAD & M & 74 & Tail & 3 & 1 & 1 & 0 & 0 & 1 & 1 & 1 & $C T$ & 12.3 & 0.5 \\
\hline BAD & $M$ & 50 & Head & 2 & 2 & 1 & 0 & 0 & 1 & 1 & 1 & $C T$ & 9.4 & 7.0 \\
\hline $\operatorname{BAD}(\mathrm{M})$ & M & 67 & Head & & & & 1 & & & & & CT & 8.3 & / \\
\hline
\end{tabular}

F: female; $M$ : male; $p G$ : pathological tumour grade; $p T$ : pathological tumour size; $p N$ : pathological lymph node status; $p M$ : pathological metastasis; $p R$ : pathological resection margin; PNI: perineural invasion; VI: vascular invasion; LVI: lymphovascular invasion; RCT: radiochemotherapy; CT: chemotherapy; OS: overall survival; DFS: disease-free survival.

IPA analysis generated networks, including 'Cell morphology', with TGFß1 (fold 2.6, $\mathrm{p}<0.001$ ) central to this network. 'Cancer', 'Cellular growth and proliferation', 'DNA repair', and 'Cellular movement' were differentially expressed functions. Differentially expressed canonical pathways $(\mathrm{p}<0.01)$ are shown in Table 2 . The Integrin pathway (including Integrin $\beta 4$ (ITGB4): fold 5.5, Integrin $\beta 5$ (ITGB5): fold 5.9, and Integrin $\alpha 6$ (ITGA6): fold 4.6; all $\mathrm{p}<0.001$ ) was most significant, followed by the Ephrin pathway (including Ephrin receptor A2 (EPHA2): fold 5.9, Ephrin receptor B2 (EPHB2): fold 3.3, Ephrin A1 (EFNA1): fold 3.4, Ephrin A4 (EFNA4): fold 2.0 and Ephrin B2 (EFNB2): fold 3.4; all p < 0.001). KEGG pathway analysis of genes overexpressed in 'Good' samples showed upregulation of elements of the p53 signalling, Wnt/ $\beta$-catenin signalling, Notch, MAPK, and Hedgehog signalling pathways (Table 2).

\section{Gene expression profiling of 'Bad' PDAC versus control}

Microarray analysis comparing 'Bad' versus control samples defined 1905 differentially expressed genes. IPA analysis on 1692 mapped genes generated networks, such as the network related to 'Drug metabolism', including TGFB1 (fold 2.4) and LOXL2 (fold 3.9), $(\mathrm{p}<0.001)$. Similar to the 'Good' versus control comparison, the functions 'Cancer,' 'Cellular growth and proliferation' and 'Cellular movement' were differentially expressed, but with even higher fold changes.

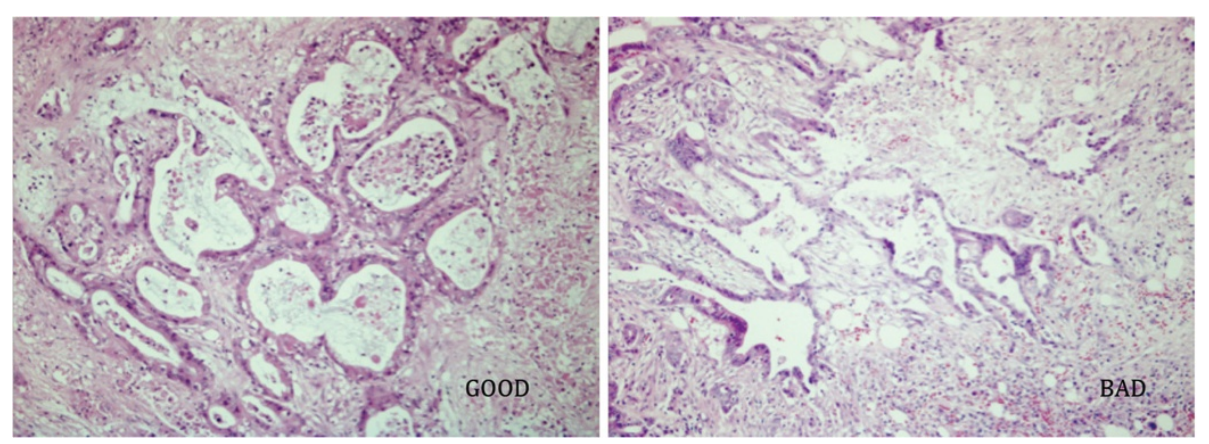

Figure 2 Pathological features from 'Good' and 'Bad' patients. Despite distinct survival data, H\&E staining on formalin fixed sections from patients from the 'Good' outcome group (left) was similar as those from the 'Bad' outcome group (right). A representative sample was shown. Original magnification 100x. 
Table 2 Differentially expressed canonical pathways (IPA) and upregulated KEGG pathways (GENECODIS) in 'Good' and 'Bad' PDAC

\begin{tabular}{|c|c|c|c|c|}
\hline \multirow[b]{2}{*}{$\begin{array}{l}\text { Canonical } \\
\text { pathways }^{\mathrm{a}}\end{array}$} & \multicolumn{2}{|c|}{ Good versus control } & \multicolumn{2}{|c|}{ Bad versus control } \\
\hline & P-value & Upregulated genes $^{c}$ & P-value & Upregulated genes $^{c}$ \\
\hline Integrin signalling & $5.62^{\mathrm{E}}-7$ & $\begin{array}{l}\text { RAC1, RAC2, ITGB4, ITGB5, ITGA6, ACTN1, } \\
\text { MAP2K2, GSK3B, PPP1R12A, ARF1, ACTG2 }\end{array}$ & $4.79^{\mathrm{E}}-6$ & $\begin{array}{l}\text { RAC1, ITGA2, ITGA3, } \\
\text { ITGA6, ITGB1, ITGB4, } \\
\text { ITGB5, ITGB6, ACTN1, } \\
\text { ARF1 }\end{array}$ \\
\hline $\begin{array}{l}\text { Ephrin receptor } \\
\text { signalling }\end{array}$ & 0.00002 & $\begin{array}{l}\text { RAC1, RAC2, EPHA2, EPHB2, EFNA4, EFNB2, } \\
\text { MAP4K4, MAP2K2, STAT3, RHOA, ADAM10, } \\
\text { VEGFA }\end{array}$ & 0.00001 & $\begin{array}{l}\text { RAC1, EFNA5, EFNB2, } \\
\text { EPHA2, EPHB4, STAT3, } \\
\text { ADAM10, FGF1, VEGFA, } \\
\text { PDGFC }\end{array}$ \\
\hline $\begin{array}{l}\text { Molecular mechanism } \\
\text { of cancer }\end{array}$ & 0.00063 & $\begin{array}{l}\text { RAC1, RAC2, CCND1, MAP2K2, TGFß1, GSK3B, } \\
\text { BRCA1, CDH1, BMP2, SMAD6, BAX, CTNNB1 }\end{array}$ & & \\
\hline P53 signalling & 0.00089 & $\begin{array}{l}\text { TP53, PIK3C2A, RAC1, BAX, BIRC5, SERPINB5, } \\
\text { GSK3B, BRCA1 }\end{array}$ & 0.02757 & $\begin{array}{l}\text { PRKDC, RAC1, BAX, CCND1, } \\
\text { BIRC5, SERPINB5, CTNNB1, } \\
\text { CDK2 }\end{array}$ \\
\hline Wnt/ß-catenin & 0.00550 & $\begin{array}{l}\text { RAC2, CSNK1A1, CSNK1E, SOX9, TGF } \beta 1, \\
\text { SOX4, LRP5, CTNNB1, WNT10A }\end{array}$ & 0.00323 & $\begin{array}{l}\text { CSNK1A1, TGFß1, DKK1, } \\
\text { DKK3, WNT5A, WNT10A, } \\
\text { SOX4, SOX11, TCF7L2, } \\
\text { TCF3 }\end{array}$ \\
\hline $\begin{array}{l}\text { Pancreatic } \\
\text { adenocarcinoma }\end{array}$ & & & 0.00776 & $\begin{array}{l}\text { JAK1, RAC1, STAT3, } \\
\text { CCND1, BIRC5, VEGF, } \\
\text { TGF } \beta 1, \text { ERBB2, CDK2 }\end{array}$ \\
\hline PI3K/AKT Signaling & 0.00933 & RAC1, RAC2, JAK1, MAP2K2, PPP2R5 & & \\
\hline \multicolumn{5}{|l|}{ KEGG pathways ${ }^{\mathrm{b}}$} \\
\hline P53 Signaling & $2.20^{\mathrm{E}}-12$ & TP53, CDKN6, CCND1, CDK1, CDK2, SFN & $3,03^{\mathrm{E}}-8$ & $\begin{array}{l}\text { CDK1, CDK2, BAX, } \\
\text { SERPINB5, CCND1, SFN }\end{array}$ \\
\hline Wnt signalling & $2,67^{\mathrm{E}}-07$ & $\begin{array}{l}\text { WNT10A, CTNNB1, CTBP1, LRP5, TCF7L2, } \\
\text { FZD8, GSK3B, PPP3R1, RAC1 }\end{array}$ & 0.00011 & $\begin{array}{l}\text { WNT5A, WNT10A, DKK1, } \\
\text { DVL1, CTNNB1, CSNK1A1, } \\
\text { CSNK1E, LRP5, RAC1, } \\
\text { TCF7L2 }\end{array}$ \\
\hline Pancreatic cancer & $3.00^{\mathrm{E}}-6$ & $\begin{array}{l}\text { TGFß1, RAC1, JAK1, VEGFA, ERBB2, STAT3,TP53, } \\
\text { RAC2 }\end{array}$ & 0.00001 & $\begin{array}{l}\text { RAC1, TGFß1, TGFa, } \\
\text { VEGFA, ERBB2, STAT3, } \\
\text { RAD51 }\end{array}$ \\
\hline NOTCH signalling & $2.40^{\mathrm{E}}-6$ & JAG1, HES1, CTBP1, CTBP2, ADAM10 & 0.00012 & DVL1, HES1, CTBP1, ADAM1C \\
\hline MAPK signalling & 0.00015 & $\begin{array}{l}\text { FGFR2, TGF } \beta 1 \text {, MAP2K5, MAP2K2, MAP2K3, } \\
\text { MAP2K7, RAC1, DUSP10, DUSP3 }\end{array}$ & & \\
\hline Hedgehog signalling & 0.00836 & CSNK1E, BMP2, GSK3B, CSNK1A1 & & \\
\hline
\end{tabular}

IPA was performed on respectively 2.806 (good) and 1.692 (bad) differentially expressed probe sets (with entry in the Ingenuity Knowledge Base; www.ingenuity. com). The most significant networks, functions and canonical pathways are listed.

${ }^{\mathrm{b}}$ KEGG analysis was performed on respectively 2.033 and 1.285 probesets upregulated in the good and bad PDAC samples using GENECODIS.

c $A$ selection of upregulated genes contributing to the pathways, is given.

Analysis of canonical pathways also revealed the Integrin pathway as most significant (including ITGA2: fold 5.0, ITGA3: fold 3.1, ITGA6: fold 5.3, ITGB1: fold 2.0, ITGB4: fold 5.8, ITGB5: fold 5.0 and ITGB6: fold 5.4; all $\mathrm{p}<0.001$ ), on top of the Ephrin receptor signalling (including EPHA2: fold 7.3, $x E P H B 4$ : fold 2.0, EFNA5: fold 3.9 and EFNB2: fold 3.0; all $\mathrm{p}<0.001)$, the $\mathrm{Wnt} / \beta$-catenin pathway and pancreatic adenocarcinoma signalling (Table 2). Genes involved in the p53 signalling pathway, the Wnt/ $\beta$-catenin and the Notch signalling were highly upregulated (Table 2) in 'Bad' PDAC samples (KEGG analysis, GENECODIS).

\section{Molecular characteristics of 'Bad' versus 'Good' PDAC}

To study gene expression profiling related to poor outcome, we first studied differentially expressed genes between 'Bad' and 'Good' PDAC samples (Figure 3A). A total of 131 genes were differentially expressed, i.e. 69 upregulated and 62 downregulated genes in 'Bad' PDAC (Table 3). The networks 'Cell morphology' (including SNAI2 (fold 2.9) and TGFBR1 (fold 3.3); $\mathrm{p}<0.001$ ), 'Cell signalling' and 'Cellular movement' were generated from differentially expressed genes (IPA). No cancer-related canonical pathways or KEGG pathways were differentially expressed between both PDAC groups. 

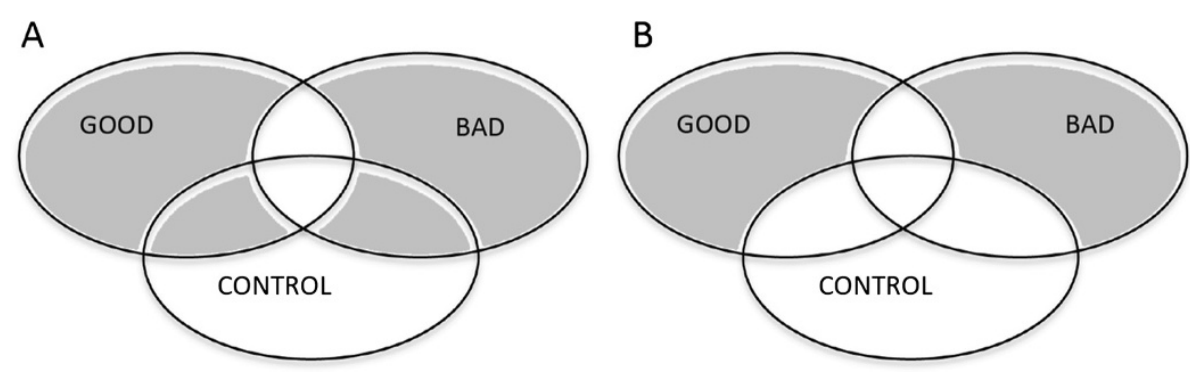

Figure 3 Molecular characteristics of 'Bad' vs. 'Good' PDAC. (A) First, genes differentially expressed between the 'Good' and the 'Bad' PDAC samples were used for IPA analysis. (B) Secondly, we compared genes differentially expressed between the 'Good' versus control and the 'Bad' versus control analysis to exclude pancreas-related genes. The control samples in both experiments were the same.

Next, we analysed differentially expressed genes between the 'Good' versus control and the 'Bad' versus control experimental designs to exclude pancreas-related genes (Figure 3B). Only genes from the MAPK and
Hedgehog signalling pathways were strongly expressed in the 'Good' samples (GENECODIS). Genes involved in Pancreatic cancer signalling pathway, p53 signalling, $\mathrm{Wnt} / \beta$-catenin and Notch signalling were expressed in

Table 3 Top 15 of differentially expressed genes, between bad versus good outcome PDAC samples

\begin{tabular}{|c|c|c|c|}
\hline Gene Symbol & Gene name & Fold bad/good & P-value \\
\hline$\overline{\mathrm{CPB} 1}$ & Carboxypeptidase B1 & 31.03 & $3.16^{\mathrm{E}}-05$ \\
\hline CTRB2 & Chymotrypsinogen B2 & 24.38 & $2.78^{\mathrm{E}}-05$ \\
\hline PLA2G1B & Phospholipase A2, group IB, pancreas & 20.35 & 0.00022 \\
\hline PNLIPRP2 & Pancreatic lipase-related protein 2 & 19.48 & 0.00019 \\
\hline PNLIP & Pancreatic lipase & 19.06 & 0.00048 \\
\hline CEL & Carboxyl ester lipase (bile salt-stimulated lipase) & 18.89 & 0.00011 \\
\hline CPA1 & Carboxypeptidase A1, pancreatic & 18.57 & $6.68^{\mathrm{E}}-05$ \\
\hline CELA3A & Chymotrypsin-like elastase family, member 3A & 17.10 & $2.47^{\mathrm{E}}-05$ \\
\hline CELA3B & Chymotrypsin-like elastase family, member 3B & 16.56 & $2.01^{\mathrm{E}}-05$ \\
\hline CPA2 & Carboxypeptidase A2 (pancreatic) & 14.43 & 0.00016 \\
\hline CLPS & Colipase, pancreatic & 11.55 & 0.00035 \\
\hline CTRC & Chymotrypsin C (caldecrin) & 11.17 & 0.00023 \\
\hline KRT6A & Keratin 6A & 10.23 & 0.00090 \\
\hline PRSS2 & Protease, serine, 2 (trypsin 2) & 8.87 & 0.00092 \\
\hline DEFA5 & Defensin, alpha 5, Paneth cell-specific & -13.95 & $9.04^{\mathrm{E}}-08$ \\
\hline SLC26A3 & Solute carrier family 26, member 3 & -13.76 & $4.08^{\mathrm{E}}-08$ \\
\hline $\mathrm{SI}$ & Sucrase-isomaltase (alpha-glucosidase) & -8.95 & $2.29^{\mathrm{E}}-07$ \\
\hline TAC3 & Tachykinin 3 & -8.06 & 0.00029 \\
\hline PRSS7 & Protease, serine, 7 (enterokinase) & -6.93 & $1.99^{\mathrm{E}}-08$ \\
\hline DEFA6 & Defensin, alpha 6, Paneth cell-specific & -6.50 & $1.50^{\mathrm{E}}-06$ \\
\hline VIP & Vasoactive intestinal polypeptide & -6.12 & $1.82^{\mathrm{E}}-05$ \\
\hline RBP2 & Retinol binding protein 2, cellula & -5.68 & $1.72^{\mathrm{E}}-07$ \\
\hline UGT2B17 & UDP glucuronosyltransferase 2 family, polypeptide B17 & -5.33 & 0.00090 \\
\hline $\mathrm{CDH} 19$ & Cadherin 19, type 2 & -4.90 & 0.00089 \\
\hline SYNM & Synemin, intermediate filament protein & -4.86 & $1.53^{\mathrm{E}}-05$ \\
\hline FOXA1 & Forkhead box A1 & -4.30 & $6.00^{\mathrm{E}}-07$ \\
\hline CLCA1 & Chloride channel accessory 1 & -3.90 & $2.05^{\mathrm{E}}-05$ \\
\hline ELF5 & E74-like factor 5 & -3.74 & $1.50^{\mathrm{E}}-06$ \\
\hline AKR1C1 & Aldo-keto reductase family 1 , member $\mathrm{C} 1$ & -3.63 & 0.00043 \\
\hline
\end{tabular}


all PDAC samples, but the constitutive genes varied. 'Bad' samples overexpressed the Wnt signalling molecules DKK1 (fold 7.9), Wnt5a (fold 3.6) and DVL1 (fold $2.8)(\mathrm{p}<0.001)$, whereas FZD8 (fold 2.7, $\mathrm{p}<0.001)$ and GSK3B (fold 2.0, $\mathrm{p}<0.001$ ) were only upregulated in 'Good' samples. TP53 was only overexpressed in the 'Good' group (fold 2.7, $\mathrm{p}<0.001$ ).

\section{Identification of metastasis-associated genes}

After excluding liver- and peritoneum specific genes, 358 genes were differentially expressed between the primary tumour and the metastatic samples. Of these genes, 278 were upregulated in primary PDAC and 80 were upregulated in metastatic tissue. Multiple networks and functions were generated from differentially expressed genes (IPA), including 'Cancer, 'Cell signalling', and 'Cell cycle'. The 'Human embryonic stem cell pluripotency' and Wnt/ $\beta$-catenin canonical pathways were significant. KEGG pathway analysis (GENECODIS) revealed expression of genes from the TGF $\beta$ and Wnt/ $\beta$ catenin pathways in primary PDAC and expression of the TGF $\beta$ pathway-related genes in metastatic tissue (Table 4). To discover pathways potentially contributing to the metastatic process, we looked for genes upregulated in the PDAC versus control experiments ('Good' versus control and 'Bad' versus control) and in the $\mathrm{Me}$ tastases versus PDAC comparison. In total 29 genes met these criteria, including $\beta$-catenin, ANP32A, HPGD, SET and SP1 (fold change between metastases versus PDAC respectively $3.0,3.4,2.5,3.6$ and 2.0 ; all $\mathrm{p}<0.001$ ) (Additional file 1: Table S1).

\section{Discussion}

Unravelling the molecular characteristics of pancreatic cancer is crucial for a better understanding of the tumour biology in order to develop novel therapeutic strategies. Correlation of gene expression profiles with patient survival might detect genes and pathways that drive PDAC invasiveness as clinicopathological parameters alone seem not sufficient to explain the variability in survival after curative resection. Therefore, in the present study, we performed whole genome expression analysis of 2 subgroups of patients with extremely diverging overall and disease-free survival rates, despite having similar clinicopathological features.
In contrast to previous studies that used microdissection or fine needle aspiration techniques to enrich the samples for neoplastic cells $[11,19,20]$, we used wholetumour samples with the aim not to exclude the tumour micro-environment even though discrimination between tumoural and environmental RNA is technically impossible in whole-tumour samples. On the other hand, PDAC is characterized by an abundant desmoplastic stromal reaction, which plays an important role in tumorigenesis, tumour progression, and therapy resistance $[12,13]$. Indeed, increasingly new therapeutic regimens are studying agents that aim to target the desmoplastic stromal reaction [21-23]. Therefore, in order to keep the molecular information of the microenvironment but to reduce background RNA contamination, we used high-quality snap-frozen samples with a pathologically proven minimum of $30 \%$ cancer cells. This approach led to a small but still representative sample size for microarray analysis.

In our study, the Integrin and Ephrin pathways were upregulated in all PDAC samples, irrespective of outcome. These pathways were not highlighted in studies on microdissected PDAC [11]. Both pathways appear to play an important role in the interaction between cancer cells and the surrounding stroma. The Integrin family of cell adhesion receptors has been implicated in tumour progression as they contribute to the interplay between tumour and micro-environment by binding directly to components of the extracellular matrix (ECM) [24]. Due to the abundance of ECM, the integrin-mediated cell adhesion signalling may play an important role in PDAC tumour growth, migration and even in therapy resistance $[25,26]$. Various integrins, such as ITGA6, ITGB4 and ITGB5, are upregulated in 'Good' and/or 'Bad' PDAC samples. In cell culture studies, ITGB1 has been shown to play a critical role in pancreatic cancer progression and in metastasis in particular $[27,28]$. Upregulation of ITGB1 in 'Bad' PDAC, might highlight its potential therapeutical impact.

Ephrin receptors are similarly promising therapeutical targets as they mediate cell-cell interactions both in tumour cells and in the tumour micro-environment, and thereby may affect tumour growth, invasiveness, angiogenesis, and metastasis [29]. EPHA2, related to poor clinical outcome in PDAC, has already been successfully investigated as target in PDAC cell lines [30,31]. Indeed, in our study, EPHA2

Table 4 Upregulated KEGG pathways (GENECODIS) in primary PDAC and metastatic PDAC samples

\begin{tabular}{|c|c|c|c|c|}
\hline \multirow[b]{2}{*}{ KEGG Pathway ${ }^{a}$} & \multicolumn{2}{|c|}{ PDAC versus Metastases } & \multicolumn{2}{|c|}{ Metastases versus PDAC } \\
\hline & P-value & Upregulated genes $^{\mathrm{b}}$ & P-value & Upregulated genes $^{\mathrm{b}}$ \\
\hline Wnt signalling & 0.00969 & FZD1, FZD10, WNT5A, CCND2 & & \\
\hline TGF $\beta$ pathway & 0.00574 & LTBP1, THBS4, MBPR1B & 0.00100 & SP1, PPP2R1B, ACVR1C \\
\hline
\end{tabular}

${ }^{a}$ KEGG analysis was performed on respectively 278 and 80 genes upregulated in the PDAC and metastases samples using GENECODIS.

${ }^{\mathrm{b}} \mathrm{A}$ selection of upregulated genes contributing to the pathways, is given. 
was highly upregulated as PDAC with poor outcome, supporting its potential clinical relevance.

Embryonic signalling pathways are known to play a role in both the tumoural and the stromal compartment and in different stages of PDAC [32]. Hedgehog signalling (Shh) e.g. has been implicated in the initiation of PDAC, and was overexpressed in PDAC samples with good overall survival in our series [33,34]. The Wnt/ $\beta$ catenin pathway seems to be involved in a later stage of PDAC tumorigenesis $[9,34,35]$. In our study, elements from the canonical $\mathrm{Wnt} / \beta$-catenin pathway were upregulated in all PDAC samples. However, in patients with poor survival, genes from both the canonical and noncanonical pathway, including $W n t 5 A$ and $D V L 1$, were upregulated [35,36]. The expression of Wnt5A has already been shown to be induced in PSC [35]. Upregulation of $D K K 1$, a Wnt/ $\beta$-catenin pathway antagonist, may promote tumour invasiveness though the exact mechanism is yet unknown [37].

Overexpression of Notch signalling in PDAC correlates with tumour proliferation and migration [38]. Notch has been shown to regulate pancreatic cancer stem cells and would have a role in the acquisition of epithelial-mesenchymal transition (EMT) by inducing SNAI2 expression due to JAG1 overexpression [39,40]. Although $J A G 1$ was upregulated in all our PDAC samples irrespective of survival, SNAI2 was upregulated in the 'Bad' versus 'Good' PDAC samples. The upregulation of many EMT-related genes, such as TGFBR1, FGFBP1, TGFB1, LOXL2, TWIST1 and Wnt5A, and the downregulation of FOXA1 in the 'Bad' PDAC samples might support the role of EMT in the aggressiveness of PDAC [41]. Additionally, upregulation of MALAT1 in the 'Bad' samples may suggest this gene to be further explored as it is upregulated in many other tumours too and associated with cancer metastasis and recurrence $[42,43]$.

Finally we identified a PDAC metastasis-related genetic profile containing 358 differentially expressed genes between the primary tumour and metastatic tissue. Molecular knowledge on the metastatic process in PDAC is currently lacking and the published data are inconsistent [9,44-46]. Moreover, the majority of studies are based on cell lines, xenograft models and rapid autopsy material. In the current study, we used fresh human samples of both liver and peritoneal metastases. In order to focus on metastasis-specific genes, we excluded tissue-associated genes, i.e. genes that were differentially expressed between liver and peritoneal tissue samples. However, in this way, we might also have excluded metastasis-specific genes. In our study, 358 genes were differentially expressed, including genes related to the $\mathrm{Wnt} / \beta$-catenin pathway and the TGF $\beta$ pathway. Comparing our differentially expressed genes with metastatic genes described in other studies, only 7 genes overlapped (COMP, PCDH7, PTP4A1,
CXCR4, NR4A3, ANGPT1 and TIMP3) [9,44-47]. A total of 29 genes were upregulated in metastases as compared to primary PDAC and control samples. One of these genes, $\beta$-catenin, may deserve further study because of several reasons. $\beta$-catenin has a role in tumorigenesis as an essential transcriptional co-activator in the canonical Wnt pathway, but it also plays a critical role in cadherinbased cell-cell adhesion [48]. $\beta$-catenin seems also to be a major determinant in EMT and in the reverse mesenchymal to epithelial transition (MET), necessary for cells to home in distant organs. Furthermore, $\beta$-catenin mediates transcription of MMP that degrade the ECM [49]. Our results support further investigation of its role in PDAC progression. Another gene, SP1 is linked with STAT3 and hence would regulate metastasis [50].

Limitations of the current study are the rather small sample size and the lack of clinical validation of our findings. These 2 concerns however, seem hard to overcome since PDAC is a rare disease of which good quality tissue is difficult to obtain. Additionally, PDAC has an abundant desmoplastic reaction that is overwhelmingly represented as compared to cancer cells, making many human tissue samples not representative. Microdissection of cancer cells might be an alternative to study PDAC, although this technique has its own inherent limitations, such as its technical difficulty and consequently its time-consuming activity, and the problem of RNA degradation [51]. Moreover, we believe that the only way to study human PDAC as a whole entity is to include its microenvironment in the analyses, especially since the latter has been shown to play a crucial role in tumour invasiveness and progression. The data from our current study might therefore provide valuable results with respect to gene expression and pathways involved in PDAC. Nonetheless, before these genes or pathways might be used as potential therapeutic targets in clinical setting, they need to be validated first either in a large number of human PDAC samples or in preclinical animal experiments.

\section{Conclusion}

The Integrin and Ephrin pathways seem to play an important role in pancreatic carcinogenesis and progression, including ITGB1 and EPHA2 as most important players. The Wnt/ $\beta$-catenin pathway and EMT might additionally contribute to PDAC progression and metastasis, with $\beta$-catenin as a central mediator. Further validation of the role of these genes and pathways is needed.

\section{Additional file}

\footnotetext{
Additional file 1: Table S1. Selection of 29 genes, upregulated in 'Good versus control', 'Bad versus control' and 'Metastases versus Pancreatic cancer (PDAC)'.
} 


\section{Abbreviations}

PDAC: Pancreatic ductal adenocarcinoma; OS: Overall survival; DFS: Diseasefree survival; EMT: Epithelial-mesenchymal transition; LM: Liver metastasis; PM: Peritoneal metastasis; H\&E: Haematoxylin-Eosin; Cl: Confidence interval; RIN:RNA: Integrity number; IPA: Ingenuity pathway analysis; KEGG: Kyoto encyclopedia of genes and genomes; ECM: Extracellular matrix.

\section{Competing interests}

The authors declare that they have no competing interests.

\section{Authors' contributions}

AVDB designed and performed the study, analysed the data and wrote the manuscript. HV participated in drafting the manuscript. RVE has been involved in analysing the data. OG contributed to data collection and data analysis and revised the manuscript. BT conceived and designed the study, interpreted the data and wrote the manuscript. All authors read and approved the final manuscript.

\section{Acknowledgements}

AVDB acknowledge support by PhD Fellow grants from the Fund for Scientific Research - Flanders (FWO-Vlaanderen) and BT acknowledges support by a research grant of the FWO.

\section{Author details}

'Department of Abdominal Surgery, University Hospitals Leuven, Leuven, Belgium. '2aboratory of Tissue Plasticity, Research Unit of Embryo and Stem Cells, Department of Development \& Regeneration, University of Leuven (KU Leuven), Leuven, Belgium. ${ }^{3}$ VIB Genomics Core, University of Leuven (KU Leuven), Leuven, Belgium. ${ }^{4}$ Department of Pathology, University Hospitals Leuven, Leuven, Belgium.

Received: 4 August 2012 Accepted: 20 August 2012

Published: 27 August 2012

\section{References}

1. Siegel R, Naishadham D, Jemal A: Cancer statistics, 2012. CA Cancer J Clin 2012, 62(1):10-29.

2. Van den Broeck A, Sergeant G, Ectors N, Van Steenbergen W, Aerts R, Topal $B$ : Patterns of recurrence after curative resection of pancreatic ductal adenocarcinoma. Eur J Surg Oncol 2009, 35(6):600-604.

3. Neoptolemos JP: Adjuvant treatment of pancreatic cancer. Eur J Cancer 2011, 47(Suppl 3):S378-S380

4. Wagner M, Redaelli C, Lietz M, Seiler CA, Friess H, Buchler MW: Curative resection is the single most important factor determining outcome in patients with pancreatic adenocarcinoma. Br J Surg 2004, 91(5):586-594.

5. Ozaki H, Hiraoka T, Mizumoto R, Matsuno S, Matsumoto Y, Nakayama T, Tsunoda T, Suzuki T, Monden M, Saitoh Y, Yamauchi H, Ogata Y: The prognostic significance of lymph node metastasis and intrapancreatic perineural invasion in pancreatic cancer after curative resection. Surg Today 1999, 29(1):16-22.

6. lacobuzio-Donahue CA, Ashfaq R, Maitra A, Adsay NV, Shen-Ong GL, Berg K, Hollingsworth MA, Cameron JL, Yeo CJ, Kern SE, Goggins M, Hruban RH: Highly expressed genes in pancreatic ductal adenocarcinomas: a comprehensive characterization and comparison of the transcription profiles obtained from three major technologies. Cancer Res 2003, 63(24):8614-8622.

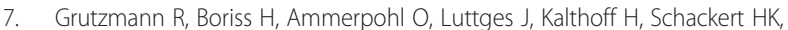
Kloppel G, Saeger HD, Pilarsky C: Meta-analysis of microarray data on pancreatic cancer defines a set of commonly dysregulated genes. Oncogene 2005, 24(32):5079-5088.

8. Kim HN, Choi DW, Lee KT, Lee JK, Heo JS, Choi SH, Paik SW, Rhee JC, Lowe AW: Gene expression profiling in lymph node-positive and lymph nodenegative pancreatic cancer. Pancreas 2007, 34(3):325-334.

9. Campagna D, Cope L, Lakkur SS, Henderson C, Laheru D, lacobuzioDonahue CA: Gene expression profiles associated with advanced pancreatic cancer. Int J Clin Exp Pathol 2008, 1(1):32-43.

10. Hirono S, Yamaue H, Hoshikawa Y, Ina S, Tani M, Kawai M, Ushijima M, Matsuura M, Saiki Y, Saiura A, Yamamoto J, Miki Y, Noda T: Molecular markers associated with lymph node metastasis in pancreatic ductal adenocarcinoma by genome-wide expression profiling. Cancer Sci 2010, 101(1):259-266.
11. Collisson EA, Sadanandam A, Olson P, Gibb WJ, Truitt M, Gu S, Cooc J, Weinkle J, Kim GE, Jakkula L, Feiler HS, Ko AH, Olshen AB, Danenberg KL, Tempero MA, Spellman PT, Hanahan D, Gray JW: Subtypes of pancreatic ductal adenocarcinoma and their differing responses to therapy. Nat Med 2011, 17(4):500-503

12. Kleeff J, Beckhove P, Esposito I, Herzig S, Huber PE, Lohr JM, Friess H: Pancreatic cancer microenvironment. Int J Cancer 2007, 121(4):699-705.

13. Farrow B, Albo D, Berger DH: The role of the tumor microenvironment in the progression of pancreatic cancer. J Surg Res 2008, 149(2):319-328.

14. Irizarry RA, Hobbs B, Collin F, Beazer-Barclay YD, Antonellis KJ, Scherf U, Speed TP: Exploration, normalization, and summaries of high density oligonucleotide array probe level data. Biostatistics 2003, 4(2):249-264.

15. Bolstad BM, Irizarry RA, Astrand M, Speed TP: A comparison of normalization methods for high density oligonucleotide array data based on variance and bias. Bioinformatics 2003, 19(2):185-193.

16. Smyth GK: Linear models and empirical bayes methods for assessing differential expression in microarray experiments. Stat Appl Genet Mol Biol 2004, 3(1):1554-6115.

17. Shi L, Reid LH, Jones WD, Shippy R, Warrington JA, Baker SC, Collins PJ, de Longueville F, Kawasaki ES, Lee KY, Luo Y, Sun YA, Willey JC, Setterquist RA, Fischer GM, Tong W, Dragan YP, Dix DJ, Frueh FW Goodsaid FM, Herman D, Jensen RV, Johnson CD, Lobenhofer EK, Puri RK, Schrf U, Thierry-Mieg J, Wang C, Wilson M, Wolber PK, et al: The MicroArray Quality Control (MAQC) project shows inter- and intraplatform reproducibility of gene expression measurements. Nat Biotechnol 2006, 24(9):1151-1161.

18. Carmona-Saez P, Chagoyen M, Tirado F, Carazo JM, Pascual-Montano A: GENECODIS: a web-based tool for finding significant concurrent annotations in gene lists. Genome Bio/ 2007, 8(1):R3.

19. Nakamura $T$, Furukawa $Y$, Nakagawa $H$, Tsunoda $T$, Ohigashi $H$, Murata K, Ishikawa O, Ohgaki K, Kashimura N, Miyamoto M, Hirano S, Kondo S, Katoh $H$, Nakamura $Y$, Katagiri T: Genome-wide cDNA microarray analysis of gene expression profiles in pancreatic cancers using populations of tumor cells and normal ductal epithelial cells selected for purity by laser microdissection. Oncogene 2004, 23(13):2385-2400.

20. Crnogorac-Jurcevic T, Efthimiou E, Nielsen T, Loader J, Terris B, Stamp G, Baron A, Scarpa A, Lemoine NR: Expression profiling of microdissected pancreatic adenocarcinomas. Oncogene 2002, 21(29):4587-4594.

21. Olive KP, Jacobetz MA, Davidson CJ, Gopinathan A, Mclntyre D, Honess D, Madhu B, Goldgraben MA, Caldwell ME, Allard D, Frese KK, Denicola G, Feig C, Combs C, Winter SP, Ireland-Zecchini H, Reichelt S, Howat WJ, Chang A, Dhara M, Wang L, Rückert F, Grützmann R, Pilarsky C, Izeradjene K, Hingorani SR, Huang P, Davies SE, Plunkett W, Egorin M, et al: Inhibition of Hedgehog signalling enhances delivery of chemotherapy in a mouse model of pancreatic cancer. Science 2009, 324(5933):1457-1461.

22. Mueller MT, Hermann PC, Witthauer J, Rubio-Viqueira B, Leicht SF, Huber S, Ellwart JW, Mustafa M, Bartenstein P, D'Haese JG, Schoenberg MH, Berger F, Jauch KW, Hidalgo $M$, Heeschen C: Combined targeted treatment to eliminate tumorigenic cancer stem cells in human pancreatic cancer. Gastroenterology 2009, 137(3):1102-1113.

23. Von Hoff DD, Ramanathan RK, Borad MJ, Laheru DA, Smith LS, Wood TE, Korn RL, Desai N, Trieu V, Iglesias JL, Zhang H, Soon-Shiong P, Shi T, Rajeshkumar NV, Maitra A, Hidalgo M: J Clin Oncol 2011, 29(34):4548-4554.

24. Desgrosellier JS, Cheresh DA: Integrins in cancer: biological implications and therapeutic opportunities. Nat Rev Cancer 2010, 10(1):9-22.

25. Grzesiak JJ, Ho JC, Moossa AR, Bouvet M: The integrin-extracellular matrix axis in pancreatic cancer. Pancreas 2007, 35(4):293-301.

26. Hazlehurst LA, Landowski TH, Dalton WS: Role of the tumor microenvironment in mediating de novo resistance to drugs and physiological mediators of cell death. Oncogene 2003, 22(47):7396-7402.

27. Arao S, Masumoto A, Otsuki M: Beta1 integrins play an essential role in adhesion and invasion of pancreatic carcinoma cells. Pancreas 2000 20(2):129-137.

28. Grzesiak JJ, Tran Cao HS, Burton DW, Kaushal S, Vargas F, Clopton P, Snyder CS, Deftos $L$, Hoffman RM, Bouvet M: Knockdown of the beta(1) integrin subunit reduces primary tumor growth and inhibits pancreatic cancer metastasis. Int J Cancer 2011, 129(12):2905-2915.

29. Pasquale EB: Eph receptors and ephrins in cancer: bidirectional signalling and beyond. Nat Rev Cancer 2010, 10(3):165-180.

30. Ansuini H, Meola A, Gunes Z, Paradisi V, Pezzanera M, Acali S, Santini C, Luzzago A, Mori F, Lazzaro D, Ciliberto G, Nicosia A, La Monica N, Vitelli A: 
Anti-EphA2 Antibodies with Distinct In Vitro Properties Have Equal In Vivo Efficacy in Pancreatic Cancer. J Oncol 2009, 2009:951917.

31. Duxbury MS, Ito H, Zinner MJ, Ashley SW, Whang EE: EphA2: a determinant of malignant cellular behavior and a potential therapeutic target in pancreatic adenocarcinoma. Oncogene 2004, 23(7):1448-1456.

32. Hezel AF, Kimmelman AC, Stanger BZ, Bardeesy N, Depinho RA: Genetics and biology of pancreatic ductal adenocarcinoma. Genes Dev 2006, 20(10):1218-1249.

33. Thayer SP, di Magliano MP, Heiser PW, Nielsen CM, Roberts DJ, Lauwers GY, Qi YP, Gysin S, Fernandez-del Castillo C, Yajnik V, Antoniu B, McMahon M, Warshaw AL: Hedgehog is an early and late mediator of pancreatic cancer tumorigenesis. Nature 2003, 425(6960):851-856.

34. Morris JP, Wang SC, Hebrok M: KRAS, Hedgehog, Wnt and the twisted developmental biology of pancreatic ductal adenocarcinoma. Nat Rev Cancer 2010, 10(10):683-695.

35. Pilarsky C, Ammerpohl O, Sipos B, Dahl E, Hartmann A, Wellmann A, Braunschweig T, Lohr M, Jesenofsky R, Friess $H$, Wente MN, Kristiansen $G$, Jahnke B, Denz A, Rückert F, Schackert HK, Klöppel G, Kalthoff H, Saeger $H D$, Grützmann R: Activation of Wnt signalling in stroma from pancreatic cancer identified by gene expression profiling. J Cell Mol Med 2008, 12(6B):2823-2835.

36. Katoh M: Transcriptional mechanisms of WNT5A based on NF-kappaB, Hedgehog, TGFbeta, and Notch signalling cascades. Int J Mol Med 2009, 23(6):763-769

37. Takahashi N, Fukushima T, Yorita K, Tanaka H, Chijiiwa K, Kataoka H: Dickkopf-1 is overexpressed in human pancreatic ductal adenocarcinoma cells and is involved in invasive growth. Int I Cancer 2010, 126(7):1611-1620.

38. Wang Z, Ahmad A, Li Y, Azmi AS, Miele L, Sarkar FH: Targeting notch to eradicate pancreatic cancer stem cells for cancer therapy. Anticancer Res 2011, 31(4):1105-1113.

39. Wang YH, Li F, Luo B, Wang XH, Sun HC, Liu S, Cui YQ, Xu XX: A side population of cells from a human pancreatic carcinoma cell line harbors cancer stem cell characteristics. Neoplasma 2009, 56(5):371-378.

40. Sarkar FH, Li Y, Wang Z, Kong D: Pancreatic cancer stem cells and EMT in drug resistance and metastasis. Minerva Chir 2009, 64(5):489-500.

41. Song Y, Washington MK, Crawford HC: Loss of FOXA1/2 is essential for the epithelial-to-mesenchymal transition in pancreatic cancer. Cancer Res 2010, 70(5):2115-2125.

42. Tano K, Mizuno R, Okada T, Rakwal R, Shibato J, Masuo Y, ljiri K, Akimitsu N: MALAT-1 enhances cell motility of lung adenocarcinoma cells by influencing the expression of motility-related genes. FEBS Lett 2010, 584(22):4575-4580.

43. Lai MC, Yang Z, Zhou L, Zhu QQ, Xie HY, Zhang F, Wu LM, Chen LM, Zheng SS: Long non-coding RNA MALAT-1 overexpression predicts tumor recurrence of hepatocellular carcinoma after liver transplantation. Med Oncol 2011, in press.

44. Niedergethmann M, Alves F, Neff JK, Heidrich B, Aramin N, Li L, Pilarsky C, Grutzmann R, Allgayer H, Post S, Gretz N: Gene expression profiling of liver metastases and tumour invasion in pancreatic cancer using an orthotopic SCID mouse model. Br J Cancer 2007, 97(10):1432-1440.

45. Nomura H, Nishimori $H$, Yasoshima T, Hata F, Tanaka H, Nakajima F, Honma T, Araya J, Kamiguchi K, Isomura H, Sato N, Denno R, Hirata K: A new liver metastatic and peritoneal dissemination model established from the same human pancreatic cancer cell line: analysis using CDNA macroarray. Clin Exp Metastasis 2002, 19(5):391-399

46. Suemizu H, Monnai M, Ohnishi Y, Ito M, Tamaoki N, Nakamura M: Identification of a key molecular regulator of liver metastasis in human pancreatic carcinoma using a novel quantitative model of metastasis in NOD/SCID/gammacnull (NOG) mice. Int J Oncol 2007, 31(4):741-751.

47. Shi WD, Meng ZQ, Chen Z, Lin JH, Zhou ZH, Liu LM: Identification of liver metastasis-related genes in a novel human pancreatic carcinoma cell model by microarray analysis. Cancer Lett 2009, 283(1):84-91.

48. Fu Y, Zheng S, An N, Athanasopoulos T, Popplewell L, Liang A, Li K, Hu C, Zhu Y: Beta-catenin as a potential key target for tumor suppression. Int $\mathrm{J}$ Cancer 2011, 129(7):1541-1551.
49. Orlichenko LS, Radisky DC: Matrix metalloproteinases stimulate epithelialmesenchymal transition during tumor development. Clin Exp Metastasis 2008, 25(6):593-600

50. Huang C, Xie K: Crosstalk of Sp1 and Stat3 signalling in pancreatic cancer pathogenesis. Cytokine Growth Factor Rev 2012, 23(1-2):25-35.

51. Decarlo K, Emley A, Dadzie OE, Mahalingam M: Laser capture microdissection: methods and applications. Methods Mol Biol 2011, 755:1-15.

doi:10.1186/1756-9966-31-68

Cite this article as: Van den Broeck et al: Molecular markers associated with outcome and metastasis in human pancreatic cancer. Journal of Experimental \& Clinical Cancer Research 2012 31:68

\section{Submit your next manuscript to BioMed Central and take full advantage of:}

- Convenient online submission

- Thorough peer review

- No space constraints or color figure charges

- Immediate publication on acceptance

- Inclusion in PubMed, CAS, Scopus and Google Scholar

- Research which is freely available for redistribution 